\title{
MÉTODOS DE CONCENTRAÇÃO DE MINERAIS 2:1 SECUNDÁRIOS NA FRAÇÃO ARGILA VISANDO SUA IDENTIFICAÇÃO POR DIFRATOMETRIA DE RAIOS $\mathrm{X}^{(1)}$
}

\author{
Vander de Freitas Melo( ${ }^{(2)}$, Julian Martins S.M. Mattos ${ }^{(3)} \&$ Valmiqui Costa Lima ${ }^{(4)}$
}

\begin{abstract}
RESUMO
Além dos baixos teores normalmente encontrados na fração argila dos solos sob clima tropical e subtropical, o tamanho reduzido e a baixa cristalinidade dos minerais 2:1 secundários dificultam sua identificação por difratometria de raios $X$ (DRX). Este estudo objetivou avaliar métodos químicos e físico de concentração de minerais 2:1 secundários na fração argila para facilitar a identificação por DRX, incluindo a natureza dos minerais quanto ao local de formação de cargas permanentes (lâmina tetraedral ou octaedral). Coletaram-se amostras de dois Cambissolos originados de argilito da Formação Guabirotuba na Bacia Sedimentar de Curitiba (PR): horizontes A, Bi, C1 (1,2 a 1,5 m), C2 (2,2 a 2,5 m), C3 (3,2 a 3,5 m) e C4 (4,2 a 4,5 m). Após remoção da matéria orgânica e dispersão da terra fina seca ao ar, a fração argila foi submetida a tratamentos sequenciais com ditionito-citratobicarbonato (DCB) (amostra desferrificada - remoção de óxidos de Fe pedogenéticos) e com soluções de $\mathrm{NaOH}$ a quente, em diferentes concentrações $\left(0,5 ; 1,0 ; 1,5 ; 2,5 ; 3,5 ; 4,0 ; 4,5\right.$ e $\left.5,0 \mathrm{~mol} \mathrm{~L}^{-1}\right)$, para extração de gibbsita e caulinita, em diferentes graus. A fração argila desferrificada também foi submetida à separação física (centrifugação) em argila grossa $(0,2$ a $2 \mu \mathrm{m})$ e fina $(<0,2 \mu \mathrm{m})$. Foram realizados tratamentos auxiliares para identificar as espécies minerais 2:1 na fração argila: saturação com Mg e solvatação com etilenoglicol; saturação com K e secagem ao ar e aquecimento a $550^{\circ} \mathrm{C}$; e saturação com Li (teste de Greene-Kelly). Os resultados mostraram que o método clássico de extração da caulinita, com solução de $\mathrm{NaOH} 5,0 \mathrm{~mol} \mathrm{~L}^{-1}$ a quente, não deve ser aplicado para concentração de minerais 2:1 secundários, pois também removeu grande parte desses minerais. O tratamento com DCB e com solução de $\mathrm{NaOH} 3,5 \mathrm{~mol} \mathrm{~L}^{-1}$ possibilitou, com maior eficiência, a concentração e identificação de minerais 2:1 secundários por DRX nas amostras dos horizontes $\mathrm{A}$, Bi e C1. Nas amostras tomadas em maiores profundidades (horizontes $\mathrm{C} 2, \mathrm{C} 3$ e C4), devido aos maiores teores desses minerais e ao menor tamanho dos cristais (argila fina), a solução menos concentrada de $\mathrm{NaOH}\left(1,5 \mathrm{~mol} \mathrm{~L}^{-1}\right)$ foi mais eficiente para esse propósito. No horizonte A, os minerais 2:1 concentraram-se na fração argila grossa, compatível com o maior grau de
\end{abstract}

\footnotetext{
(1) Recebido para publicação em outubro de 2008 e aprovado em março de 2009.

(2) Professor do Departamento de Solos e Engenharia Agrícola, Universidade Federal do Paraná - UFPR. Rua dos Funcionários, 1540, CEP 80035-050 Curitiba (PR). Bolsista CNPq. vanderfm@ufpr.br.

(3) Acadêmica do Curso de Agronomia, UFPR. Bolsista PIBIC/CNPq. E-mail: julianmsmm@hotmail.com

(4) Professor do Departamento de Solos e Engenharia Agrícola, UFPR. E-mail: valmiqui@ufpr.br
} 


\begin{abstract}
intemperismo desse horizonte. Identificou-se esmectita com hidroxi-Al entrecamadas nos horizontes mais superficiais (A e Bi) e esmectita nas amostras do horizonte C. A saturação com Li permitiu a identificação das esmectitas dioctaedrais montmorilonita e beidelita/nontronita. As adaptações ao métodopadrão ( $\left.\mathrm{NaOH} 5 \mathrm{~mol} \mathrm{~L}^{-1}\right)$ favoreceram a concentração de minerais 2:1 secundários na fração argila dos solos; a concentração da solução de $\mathrm{NaOH}$ deve ser maior para horizontes com menor teor do mineral.
\end{abstract}

Termos de indexação: esmectita, montmorilonita, beidelita, nontronita, extração sequencial.

\title{
SUMMARY: METHODS FOR CONCENTRATING SECONDARY 2:1 MINERALS IN THE CLAY FRACTION FOR SUBSEQUENT IDENTIFICATION BYX-RAY DIFRACTOMETRY
}

\begin{abstract}
Besides the typically low levels of secondary 2:1 minerals found in the clay fraction of soils in tropical and subtropical climates, the small mineral size and low crystallinity make their analyses by X-ray difractometry (XRD) difficult. This study aimed to evaluate physical and chemical methods for concentrating secondary 2:1 minerals in the clay fraction to facilitate their identification by XRD. Also, it was sought to analyze the nature of the minerals regarding the sites of origin of permanent charges (tetrahedral or octahedral sheets). Samples were collected in two Cambisols originated from argillite of the Guabirotuba formation in the sedimentary basin of Curitiba (PR), Brazil, in the horizons: A, Bi, C1 (1.2 to $1.5 \mathrm{~m})$, C2 (2.2 to $2.5 \mathrm{~m})$, C3 $(3.2$ to $3.5 \mathrm{~m})$ and $C 4(4.2$ to $4.5 \mathrm{~m})$. After removing the organic matter and dispersing the airdried fine earth, the clay was sequentially treated with dithionite-citrate-bicarbonate $(D C B)$ (iron-free sample - removal of pedogenetic iron oxides) and with hot $\mathrm{NaOH}$ solutions at different concentrations $\left(0.5,1.0,1.5,2.5,3.5,4.0,4.5\right.$, and $\left.5.0 \mathrm{~mol} \mathrm{~L}^{-1}\right)$ for kaolinite and gibbsite extraction at different degrees. The iron-free clay fraction was also physically separated (centrifugation) in coarse $(0.2$ to $2 \mu \mathrm{m})$ and fine clay $(<0.2 \mu \mathrm{m})$. Secondary treatments were performed to identify the 2:1 mineral species in the clay fraction: saturation with $\mathrm{Mg}$ and solvation with ethylene glycol, $K$ saturation, air-drying and heating to $550{ }^{\circ} \mathrm{C}$; and Li saturation (Greene-Kelly test). Results showed that the classical method of kaolinite extraction with hot $5.0 \mathrm{~mol} \mathrm{~L}^{-1} \mathrm{NaOH}$ solution should not be used to concentrate secondary 2:1 minerals because the solution also removed a large portion of these minerals. The treatment with DCB and with $3.5 \mathrm{~mol} \mathrm{~L}^{-1} \mathrm{NaOH}$ solution was more efficient to concentrate and favored the identification of secondary 2:1 minerals by XRD in samples of the $A, B i$ and $C 1$ horizons. In samples from greater soil depths (C2, C3 and C4 horizons), due to the higher levels of these minerals and the smaller crystal size (fine clay), a less concentrated $\mathrm{NaOH}$ solution (1.5 $\left.\mathrm{mol} \mathrm{L}^{-1}\right)$ was more efficient for this purpose. In A horizon, 2:1 minerals were concentrated in the coarse clay fraction, what is compatible with the higher weathering degree of this horizon. Smectite with Al-hydroxy interlayers was identified in most surface horizons (A and Bi) and smectite was found in the Chorizon samples. Li saturation made the identification of dioctaedral minerals (montmorillonite and beidellite/nontronite) possible. The modification of the standard method (5 mol L-1 $\mathrm{NaOH}$ ) favored the concentration of secondary 2:1 minerals in the soil clay fraction; the concentration of the $\mathrm{NaOH}$ solution must be higher for horizons with lower mineral content.
\end{abstract}

Index terms: smectite, montmorillonite, beidellite, nontronite, sequential extraction.

\section{INTRODUÇÃO}

A montmorilonita, representante do grupo das esmectitas de maior ocorrência nos solos, apresenta alta área superficial específica (ASE) e substituição isomórfica, preferencialmente na lâmina octaédrica $\left(\mathrm{Al}^{3+}\right.$ por $\left.\mathrm{Mg}^{2+}\right)$, responsável pela elevada CTC do mineral, com valor médio de $100 \mathrm{cmol}_{\mathrm{c}} \mathrm{kg}^{-1}$ (Borchardt, 1989; Schulze, 1989).
As esmectitas normalmente são formadas pelo intemperismo de micas e vermiculitas, processo conhecido como diagênese, e pela conservação de parte das camadas 2:1 (Schulze, 1989; McBride, 1994). Outra possibilidade importante é a neogênese a partir da liberação de Al, Si e bases na solução do solo pelo intemperismo simultâneo de minerais primários silicatados (p.ex., feldspatos, olivinas magnesianas, hornblendas, etc.), em condições de baixa a moderada 
lixiviação de sílica (Churchman, 2000; Reid-Soukup \& Ulrey, 2002). No Brasil, solos ricos em esmectitas podem ser encontrados na região semiárida, no pampa e no pantanal (Melfi et al., 2004). No Nordeste, sua ocorrência e permanência está associada ao clima bastante seco, sem excedente hídrico, que desfavorece a dessilicação (Corrêa et al., 2003); no Sul, ao paleoclima seco (Bombin \& Klamt, 1974); e no Pantanal, às condições de drenagem impedida. Apesar dessa tendência geral, podem-se encontrar solos ricos em esmectitas no Brasil, associados às condições locais específicas atuais ou do passado geológico recente, como os Vertissolos (Volkoff \& Ribeiro, 1979; Ribeiro et al., 1990; Moniz et al., 1990; Corrêa et al., 2003).

A identificação de minerais 2:1 por difratometria de raios X (DRX) é baseada nas reflexões basais (00l), que permitem quantificar a expansão das camadas em função da saturação dos sítios de adsorção com íons específicos (K e Mg), líquidos orgânicos polares (glicerol, etilenoglicol) e aquecimento (100, 350 e $550{ }^{\circ} \mathrm{C}$ ) (Whittig \& Allardice, 1986). Vários autores têm associado esses e outros procedimentos à DRX para tornar a técnica mais sensível e precisa na identificação e quantificação de minerais 2:1. Amostras de argila com picos largos (grande largura à meia altura) entre $\mathrm{d}(001)=0,72 \mathrm{e} 0,75 \mathrm{~nm}$ foram tratadas com etilenoglicol (deslocamento em direção aos ângulos pequenos - expansão das entrecamadas) e aquecidas a $300{ }^{\circ} \mathrm{C}$ (fechamento das entrecamadas) por Bortoluzzi et al. (2007), para identificação de mineral interestratificado caulinita (Ct)/esmectita (Es). Em DRX modelado (uso de argilas de referência e programas específicos), estes autores confirmaram a presença de $\mathrm{Ct} / \mathrm{Es}$, na proporção de 0,1 a 0,2 de camadas de Es. Drits et al. (2005) e Barré et al. (2008) trataram amostras com $\mathrm{NH}_{4}{ }^{+}$e K para estudar ilita/ ES por meio de programas de decomposição dos difratogramas.

Os estudos de minerais 2:1 com hidroxi-Al entrecamadas por DRX normalmente são realizados antes e após o tratamento químico da argila para remoção dos polímeros (p.ex., $\mathrm{NaOH} 0,5 \mathrm{~mol} \mathrm{~L}^{-1}$ - Melo et al., 2002; citrato de $\mathrm{Na} 0,3 \mathrm{~mol} \mathrm{~L}^{-1} \mathrm{pH} \mathrm{7,3-Pai} \mathrm{et}$ al., 2004). O aquecimento da amostra a $550{ }^{\circ} \mathrm{C}$ por quatro horas também promove a destruição das ilhas de hidroxi-Al e o colapso do mineral, onde o espaçamento basal passa de 1,4 para 1,0 $\mathrm{nm}$ (Whittig \& Allardice, 1986).

De acordo com Kahle et al. (2002), pelo menos quatro métodos gerais de quantificação de minerais por DRX são frequentemente utilizados em amostras de solo: (a) método do padrão interno - adição de substância-padrão à mistura em uma proporção conhecida; (b) método dos coeficientes de atenuação; (c) método do ajuste de perfis completos - refinamento estrutural de Rietveld; e (d) relação das intensidades dos picos dos minerais (fator de intensidade mineral). Em estudos ainda mais específicos, a interação da espectroscopia de ressonância magnética de alta resolução (MAS NMR) com a DRX permitiu a identificação das coordenações do $\mathrm{Al}^{3+}$ (octaédrica e tetraédrica) na estrutura de minerais 2:1 (Alba et al., 2004). Ainda nos métodos físicos, a microscopia eletrônica de transmissão e a microscopia de força atômica também têm sido amplamente utilizadas para identificação e estudos morfológicos das esmectitas (Tournassat et al., 2003; Dur et al., 2004).

O expressivo aumento dos valores de CTC e de ASE de amostras de argila com extrações seletivas e sequenciais de minerais é utilizado como evidência de esmectita nos solos (Ndayiragije \& Delvaux, 2003; Souza Júnior et al., 2007). O método-padrão para concentração de minerais $2: 1$ na argila (extração de óxidos de $\mathrm{Fe}$ com ditionito-citrato-bicarbonato de $\mathrm{Na}$ (DCB) e gibbsita e minerais 1:1 com $\mathrm{NaOH} 5 \mathrm{~mol} \mathrm{~L}^{-1}$ a quente) foi desenvolvido para solos de clima temperado (Mehra \& Jackson, 1960; Norrish \& Taylor, 1961; Jackson, 1979; Jackson et al., 1986). Com o uso desses métodos em extração sequencial, Melo et al. (2002, 2003) e Souza Júnior et al. (2007) observaram aparecimento ou incremento da intensidade das reflexões basais de minerais 2:1 na fração argila concentrada.

A extração com solução de $\mathrm{NaOH} 5 \mathrm{~mol} \mathrm{~L}^{-1}$, conduzida por $1,5 \mathrm{~h}$ a $250{ }^{\circ} \mathrm{C}$, possui alta capacidade de extração de diferentes minerais secundários com Al no solo, principalmente gibbsita e a lâmina octaédrica de caulinita e haloisita (Jackson et al., 1986). Em princípio, a solubilização dos minerais 2:1 dioctaedrais seria dificultada devido à "proteção" da lâmina de octaedros de $\mathrm{Al}$ pelas duas lâminas de tetraedros de Si. Contudo, essa premissa precisa ser validada, sobretudo para amostras com baixos teores de esmectita e com partículas de pequeno tamanho e baixa cristalinidade.

Dessa forma, o objetivo deste trabalho foi avaliar métodos químicos e físico de concentração de minerais 2:1 secundários na fração argila, para facilitar a identificação destes por DRX. Procurou-se, também, por meio de tratamentos químicos, identificar o tipo de mineral de argila $2: 1$, incluindo a natureza quanto ao local de formação de cargas permanentes (lâmina tetraedral ou octaedral).

\section{MATERIAL E MÉTODOS}

\section{Área de estudo e amostragem de solos}

As áreas estão localizadas no domínio geomorfológico do primeiro planalto paranaense, no qual se encontra a Bacia Sedimentar de Curitiba. De acordo com a classificação de Köppen, o clima da região de Curitiba é do tipo $\mathrm{Cfb}$, definido como mesotérmico úmido e superúmido. A temperatura média anual é de $16,5^{\circ} \mathrm{C}$, sendo $20,4{ }^{\circ} \mathrm{C}$ nos meses mais quentes e $12,7^{\circ} \mathrm{C}$ nos meses mais frios, com ocorrência frequente de geadas severas. A precipitação - média anual entre 1.400 e 
$1.500 \mathrm{~mm}$ - é distribuída por todos os meses, estando a umidade relativa do ar em torno de $81 \%$ (Maack, 1969).

A formação geológica dessa Bacia provém do Período Quaternário, dividida em Pleistocênio e Holocênio, definida como Formação Guabirotuba (Bigarella \& Salamuni, 1962). Essa formação consiste de depósitos pouco consolidados, litologicamente constando de argilitos, arenitos e arcóseos (Salamuni \& Stellfeld, 2001). A Bacia apresenta cerca de $3.000 \mathrm{~km}^{2}$, e a espessura do pacote de sedimentos varia de 1 a $85 \mathrm{~m}$. Alguns autores apresentaram dados mineralógicos do argilito da Formação Guabirotuba, evidenciando o predomínio de mineral do grupo das esmectitas, possivelmente montmorilonita (Massad et al., 1981), compatível com a deposição dos sedimentos sob paleoclima semiárido (Lima et al., 1985). Contudo, a fração argila de Cambissolos e de Latossolos da área são essencialmente cauliníticas (teores variando de 662 a $725 \mathrm{~g} \mathrm{~kg}^{-1}$ - Pires et al., 2007).

Foram selecionados um perfil de Cambissolo Húmico distrófico típico (Embrapa, 2006), localizado na Fazenda Experimetal do Canguiri (FAZ) da Universidade Federal do Paraná (UFPR) (Pinhais, PR), e um perfil de Cambissolo Húmico alumínico típico, localizado no Setor de Ciências Agrárias (SCA) da UFPR (Curitiba, PR). De acordo com Embrapa (1984), o Cambissolo é a classe de maior ocorrência na região de Curitiba, com aproximadamente $60 \%$ de representatividade espacial. O relevo local da primeira área é ondulado, e o perfil $\mathrm{FAZ}$ está localizado no terço superior de encosta. A ocorrência de Latossolos nessa área limita-se às posições mais planas dos topos de elevação e das partes baixas de transição entre os Cambissolos e os solos hidromórficos. Já o perfil SCA localiza-se em relevo praticamente plano, sem a ocorrência de Latossolos na área, pela drenagem imperfeita do regolito e do argilito. As principais características morfológicas dos perfis, determinadas segundo Lemos \& Santos (2005), são apresentadas no quadro 1.

Foram coletadas seis amostras deformadas de cada Cambissolo (total de 12 amostras): horizontes $\mathrm{A} \mathrm{e} \mathrm{Bi} \mathrm{-}$ coleta em toda a extensão dos horizontes (Quadro 1); horizonte C1 - 1,2 a 1,5 m; horizonte C2 - 2,2 a 2,5 m; horizonte C3 - 3,2 a 3,5 m; e horizonte C4 - 4,2 a 4,5 m. As amostras dos horizontes A, Bi e C1 foram coletadas em trincheiras, e as dos horizontes mais profundos, por tradagem. Quanto às análises químicas e mineralógicas, as amostras foram secas ao ar e passadas em peneira de $2 \mathrm{~mm}$, para obtenção da terra fina seca ao ar (TFSA).

\section{Preparação das amostras e separação das frações do solo}

As amostras de TFSA foram tratadas com peróxido de hidrogênio a $30 \%(\mathrm{v} / \mathrm{v})$ para remoção de matéria orgânica e com $\mathrm{NaOH} 0,2 \mathrm{~mol} \mathrm{~L}^{-1}$ para dispersão das partículas (Jackson, 1979; Kunze \& Dixon, 1986). Após esses tratamentos prévios, a fração areia foi retida em peneira de $0,053 \mathrm{~mm}$, e as frações argila e silte, recolhidas em provetas de $1.000 \mathrm{~mL}$ e separadas por sedimentação com base na lei de Stokes (Gee \& Bauder, 1986). A argila obtida nessa etapa foi denominada "natural", por ainda não ter sido submetida a nenhum tratamento específico.

\section{Extração de óxidos de ferro pedogenéticos da fração argila}

Realizou-se a desferrificação das amostras de argila natural com ditionito-citrato-bicarbonato de $\mathrm{Na}$ (DCB)

Quadro 1. Características morfológicas dos perfis de Cambissolos da Região Metropolitana de Curitiba

\begin{tabular}{|c|c|c|c|c|c|c|}
\hline \multirow{2}{*}{ Perfil/classe $^{(1)}$} & \multirow{2}{*}{ Horizonte $^{(2)}$} & \multirow{2}{*}{ Profundidade } & \multirow{2}{*}{ Textura } & \multirow{2}{*}{$\begin{array}{l}\text { Cor úmida } \\
\text { Munsell }\end{array}$} & \multirow{2}{*}{ Estrutura $^{(4)}$} & Consistência $^{(5)}$ \\
\hline & & & & & & $\overline{\text { Seco, Úmido, Molhado }}$ \\
\hline & & $\mathrm{cm}$ & & & & \\
\hline \multirow[t]{3}{*}{ FAZ/CHd } & $\mathrm{A}$ & $0-36$ & Argilosa & 10YR 4/4 & $\mathrm{M}, \mathrm{M}$ a $\mathrm{G}, \mathrm{BS}$ & $\mathrm{D}, \mathrm{Fr}, \mathrm{Pl}$ e $\mathrm{Pg}$ \\
\hline & $\mathrm{Bi}$ & $56-88$ & Argilosa & $2,5 \mathrm{YR} 5 / 8$ & $\mathrm{M}, \mathrm{G}, \mathrm{BS}$ & $\mathrm{D}, \mathrm{Fi}, \mathrm{Pl}$ e $\mathrm{Pg}$ \\
\hline & $\mathrm{C}$ & $113^{+}$ & Argilosa & (3) & (4) & $\mathrm{D}, \mathrm{Fi}, \mathrm{Pl}$ e $\mathrm{Pg}$ \\
\hline \multirow[t]{3}{*}{$\mathrm{SCA} / \mathrm{CHa}$} & $\mathrm{A}$ & $0-38$ & Argilosa & 10YR $4 / 4$ & $\mathrm{M}, \mathrm{M}, \mathrm{G}$ & $\mathrm{D}, \mathrm{Fr}, \mathrm{Pl}$ e $\mathrm{Pg}$ \\
\hline & $\mathrm{Bi}$ & $57-85$ & Argilosa & 10YR 7/4 & $\mathrm{F}, \mathrm{G}, \mathrm{P}$ & $\mathrm{MD}, \mathrm{Fi}, \mathrm{MPl}$ e $\mathrm{MPg}$ \\
\hline & $\mathrm{C}$ & $110^{+}$ & Argilosa & (3) & (4) & $\mathrm{MD}, \mathrm{MFi}, \mathrm{MPl}$ e $\mathrm{MPg}$ \\
\hline
\end{tabular}

(1) FAZ: perfil localizado na Fazenda Experimetal do Canguiri (FAZ) da Universidade Federal do Paraná (UFPR) (Pinhais, PR); SCA: perfil localizado no Setor de Ciências Agrárias (SCA) da UFPR (Curitiba, PR); CHd: Cambissolo Húmico distrófico típico; CHa: Cambissolo Húmico alumínico típico. ${ }^{(2)}$ A morfologia dos horizontes de transição (AB, BA e BC) não foi apresentada. (3) Coloração variegada composta por vermelho (10R 5/8) e cinzento brunado claro (5PB 7/1). No horizonte C, abaixo de $140 \mathrm{~cm}$, do perfil SCA tem-se a ocorrência de mosqueado proeminente comum médio preto azulado (5 PB 2,5/1). ${ }^{(4)}$ Estrutura: grau de desenvolvimento (F: forte, M: moderado), tamanho (M: médio, G: grande), tipo (G: granular, BS: bloco subangular, P: prismática). Estrutura do horizonte C: maciça que se desfaz em pequena a média blocos angulares. ${ }^{(5)}$ Consistência no estado seco: D: duro, MD: muito duro; estado úmido: Fr: friável, Fi.: firme, MFi: muito firme; estado molhado (plasticidade e pegajosidade): Pl: plástico, MPl: muito plástico, Pg: pegajoso, MPg: muito pegajoso. 
(Mehra \& Jackson, 1960). Para isso, pesaram-se 2,5 g de argila (balança de quatro dígitos) em tubos de centrífuga com capacidade de $100 \mathrm{~mL}$, aos quais foram adicionados $40 \mathrm{~mL}$ de solução de citrato de $\mathrm{Na}$ $0,3 \mathrm{~mol} \mathrm{~L}^{-1}, 5 \mathrm{~mL}$ de bicarbonato de $\mathrm{Na} 1 \mathrm{~mol} \mathrm{~L}^{-1} \mathrm{e}$ $1 \mathrm{~g}$ de ditionito de $\mathrm{Na}$ em pó. Essa mistura foi mantida em banho-maria por $30 \mathrm{~min}$ a $70^{\circ} \mathrm{C}$; após $15 \mathrm{~min}$ iniciais, foi adicionada outra porção de $1 \mathrm{~g}$ de ditionito, agitando-se continuamente. A suspensão foi centrifugada a $3.500 \mathrm{rpm}$ por 10 min e o sobrenadante descartado. O procedimento foi repetido mais três vezes (total de quatro extrações). O excesso de sais foi removido no final das extrações, lavando-se o resíduo duas vezes com $80 \mathrm{~mL}$ de $\left(\mathrm{NH}_{4}\right)_{2} \mathrm{CO}_{3} 0,5 \mathrm{~mol} \mathrm{~L}^{-1} \mathrm{e}$ uma vez com $80 \mathrm{~mL}$ de água deionizada. Em seguida, a quantidade de material removido pelo DCB foi obtida pela diferença de massa da amostra seca em estufa a $60{ }^{\circ} \mathrm{C}$ por $24 \mathrm{~h}$, antes e após a extração. A fim de obter-se quantidade suficiente de argila desferrificada para as análises subsequentes, o tratamento com DCB foi realizado em 10 repetições, ou seja, utilizaram-se $25 \mathrm{~g}$ de cada amostra de argila natural.

Extração de gibbsita e caulinita, em diferentes graus, e concentração de minerais 2:1 secundários na fração argila

As amostras de argila desferrificada (DCB) foram tratadas com solução de $\mathrm{NaOH}$ a quente por meio de fervura a $250{ }^{\circ} \mathrm{C} \mathrm{em}$ banho-de-areia, pelo período de 1,5 h (Norrish \& Taylor, 1961; Singh \& Gilkes, 1991). Foram adotadas as seguintes concentrações de $\mathrm{NaOH}$ $\left(\mathrm{mol} \mathrm{L}^{-1}\right): 0,5 ; 1,0 ; 1,5 ; 2,5 ; 3,5 ; 4,0 ; 4,5$; e 5,0. Após cada extração, as amostras foram centrifugadas e o sobrenadante descartado. Para remover a sodalita formada [ $\mathrm{Na}_{4} \mathrm{Al}_{3} \mathrm{Si}_{3} \mathrm{O}_{12}(\mathrm{OH})$ ], foram efetuadas duas lavagens do resíduo com $90 \mathrm{~mL}$ de $\mathrm{HCl} 0,5 \mathrm{~mol} \mathrm{~L}^{-1}$ (Norrish \& Taylor, 1961), com tempo de contato de 10 min para cada lavagem (Singh \& Gilkes, 1991). O resíduo foi lavado, e a massa de amostra removida foi determinada conforme descrito anteriormente.

\section{Identificação dos minerais 2:1 secundários da fração argila por difratometria de raios X(DRX)}

Foram realizados tratamentos auxiliares nas amostras de argila [desferrificada (DCB) (todos os horizontes) e desferrificada e tratada com $\mathrm{NaOH}$ $3,5 \mathrm{~mol} \mathrm{~L}^{-1}$ (horizontes $\mathrm{A}$, Bi e C1) e com $\mathrm{NaOH}$ $1,5 \mathrm{~mol} \mathrm{~L}^{-1}$ (horizontes C2, C3 e C4)] para identificar os minerais 2:1 secundários por DRX: (a) saturação com $\mathrm{Mg}$ e secagem ao ar para diferenciar minerais 2:1 expansíveis (vermiculita e esmectita) dos não expansíveis (micas); (b) saturação com Mg e solvatação com etilenoglicol para diferenciar vermiculita de esmectita; (c) saturação com K e secagem ao ar para diferenciar clorita e vermiculita ou esmectita com hidroxi-Al entrecamadas (VHE ou EHE) de minerais 2:1 expansíveis; (d) saturação com $\mathrm{K}$ e aquecimento a $500{ }^{\circ} \mathrm{C}$ para diferenciar clorita de VHE ou EHE (Whittig \& Allardice, 1986); (e) como as esmectitas dioctaedrais montmorilonita e beidelita/nontronita se distinguem pela substituição isomórfica nos octaedros ou tetraedros, respectivamente, foi aplicado o teste de Greene-Kelly (1953), modificado por Lim \& Jackson (1986). As amostras foram saturadas com solução de $\mathrm{LiCl} 1 \mathrm{~mol} \mathrm{~L}^{-1}$. Empregaram-se três saturações, com agitação individual por $8 \mathrm{~h}$ em agitador orbital. Os excessos de $\mathrm{Li} \mathrm{e} \mathrm{Cl}$ foram removidos por três lavagens com etanol 80 \% e uma com água deionizada. Lâminas com as amostras orientadas foram montadas, secas lentamente ao ar e colocadas em mufla a $250^{\circ} \mathrm{C}$ por $24 \mathrm{~h}$. Estas lâminas foram analisadas por DRX antes e após a saturação com vapor de etilenoglicol a $110^{\circ} \mathrm{C}$ por $24 \mathrm{~h}$.

Os difratogramas das amostras orientadas, preparadas sobre lâminas de vidro, foram obtidos usando difratômetro com goniômetro vertical da marca Philips, modelo PW 1050/70, com velocidade angular do goniômetro de $1^{\circ} 2 \theta \mathrm{min}^{-1}$, equipado com tubo de $\mathrm{Cu}$ e filtro de $\mathrm{Ni}$. O tubo de raios $\mathrm{X}$ foi operado a $20 \mathrm{~mA}$ e $40 \mathrm{kV}$. As seguintes amplitudes de varreduras por DRX foram empregadas nas diferentes amostras de argila: 2 a $40^{\circ} 2 \theta$ - natural, desferrificada (DCB) e tratada sequencialmente com DCB e com $\mathrm{NaOH}$ (todas as concentrações); e amplitude de varredura de 2 a $15^{\circ} 2 \theta$ - tratamentos auxiliares (saturação com Li, Mg, Mg mais etilenoglicol, K e K mais aquecimento).

\section{Separação da fração argila em duas classes de tamanho}

Para obtenção de fração argila grossa $(0,2$ a $2 \mu \mathrm{m})$ e fina $(<0,2 \mu \mathrm{m})$ (Jackson, 1979), amostras desferrificadas (DCB) dos horizontes A e C4 foram submetidas à dispersão com água $\mathrm{pH} 10(0,1 \mathrm{~g}$ de $\mathrm{Na}_{2} \mathrm{CO}_{3}$ em $1 \mathrm{~L}$ de água deionizada). Para auxiliar na dispersão, colocaram-se esferas de aço (diâmetro de $2 \mathrm{~mm}$ ) no interior de cada recipiente, e a suspensão foi agitada por $4 \mathrm{~h}$ em agitador orbital. Após a retirada das esferas, procedeu-se à centrifugação a $6.000 \mathrm{rpm}$ por 7 min a $25{ }^{\circ} \mathrm{C}$. Para obtenção da percentagem de cada fração, tomou-se a massa seca inicial da argila desferrificada $\left(60^{\circ} \mathrm{C}\right.$ por $\left.24 \mathrm{~h}\right)$ e as massas secas das frações argila grossa e fina, após procedimento de separação. As amostras de cada classe de tamanho também foram submetidas à DRX, numa amplitude de varredura de 2 a $15^{\circ} 2 \theta$.

\section{Eficiência na concentração de minerais 2:1 secundários}

A eficiência do método químico e físico na concentração dos minerais $2: 1$ secundários na fração argila foi avaliada em relação a intensidade e melhor definição [pico mais agudo e com menor largura à meia altura (LMH)] da reflexão (001) do mineral por DRX. A cristalinidade e o diâmetro médio dos cristais dos filossilicatos da fração argila apresentam relação inversa com a LMH de suas reflexões basais (Klug \& Alexander, 1954; Melo et al., 2001). 


\section{RESULTADOS E DISCUSSÃO}

\section{Identificação de minerais 2:1}

A identificação dos minerais 2:1 secundários na fração argila por difratometria de raios X (DRX) foi facilitada mediante a remoção parcial de óxidos de Fe, gibbsita e caulinita, com consequente concentração da amostra (Figuras 1 e 2); observa-se que as reflexões basais (001) das amostras tratadas sequencialmente com DCB e com soluções menos concentradas de $\mathrm{NaOH}$ foram mais intensas e com menor largura à meia altura (LMH). Pires et al. (2007) trabalharam com amostras dos horizontes $\mathrm{A}$, Bi e $\mathrm{C}$ do mesmo perfil de Cambissolo da Fazenda Experimental do Canguiri (FAZ) e encontraram, respectivamente, os seguintes teores de minerais: óxidos de Fe (hematita mais goethita) - 144, 122 e $29 \mathrm{~g} \mathrm{~kg}^{-1}$; caulinita - 684, $722 \mathrm{e}$ $719 \mathrm{~g} \mathrm{~kg}^{-1}$; e gibbsita - 157, 86 e $81 \mathrm{~g} \mathrm{~kg}^{-1}$. Esses resultados evidenciam a natureza caulinítica, com menor ocorrência de óxidos de $\mathrm{Fe}$ e $\mathrm{Al}$, dos Cambissolos da área de estudo, diferente do predomínio de esmectita na rocha de origem (Massad et al., 1981).

De acordo com Jackson et al. (1986), o tratamento com $\mathrm{NaOH} 5 \mathrm{~mol} \mathrm{~L}^{-1}$ a quente deve ser empregado em amostras de argila, previamente submetidas ao DCB, nos estudos de extrações seletivas de minerais, com o objetivo de concentrar minerais filossilicatos $2: 1$, tectossilicatos (quartzo e feldspatos) e óxidos refratários (p.ex., anatásio). Outros autores utilizaram essa mesma sequência de extrações de óxido de Fe, gibbsita e caulinita para concentrarem minerais $2: 1$ e tectossilicatos (Melo et al., 2002, 2003; Souza Júnior et al., 2007); contudo, não confirmaram se ocorreu remoção simultânea de minerais $2: 1$. No presente estudo, o método de extração com solução de $\mathrm{NaOH}$ $5,0 \mathrm{~mol} \mathrm{~L}^{-1}$ removeu também grande parte dos minerais 2:1 secundários, o que reduziu a intensidade da reflexão basal (001) desse grupo de minerais (Figuras 1 e 2). O d(001) na posição dos cumes das reflexões basais das amostras dos horizontes $\mathrm{A} \mathrm{e} \mathrm{C} 4$ tratadas com DCB e $\mathrm{NaOH} 5 \mathrm{~mol} \mathrm{~L}^{-1}$ está em torno de $1,0 \mathrm{~nm}\left(8,9{ }^{\circ} 2 \theta\right)$, uma vez que a remoção dos minerais 2:1 secundários favoreceu a reflexão da ilita/ mica. Provavelmente, o reduzido tamanho e a baixa cristalinidade dos minerais facilitaram a dissolução das lâminas de octaedros de $\mathrm{Al}$ das camadas 2:1 com as soluções mais concentradas de $\mathrm{NaOH}$.

As variações no espaçamento basal entre os demais tratamentos (Figuras 1 e 2) podem ser atribuídas, entre outras, à dissolução de ilhas de hidroxi-Al com as soluções de $\mathrm{NaOH}$, à remoção preferencial de cristais menores de minerais $2: 1$ com as soluções de $\mathrm{NaOH}$ e à possibilidade do aparecimento de reflexões de minerais interestratificados. Para os minerais 1:1, os cristais com menor tamanho no eixo $c$ apresentam ligeiro aumento da distância basal (Koppi \& Skjemstad, 1981). No horizonte A do perfil SCA, o tratamento com $\mathrm{NaOH} 0,5 \mathrm{~mol} \mathrm{~L}^{-1}$, em relação à amostra tratada apenas com DCB, ampliou a intensidade da reflexão basal, mas o d(001) foi mantido em torno de 1,26 nm (Figura 1). Já o ataque da amostra com DCB e NaOH $1 \mathrm{~mol} \mathrm{~L}^{-1}$ promoveu a redução da intensidade e uma sutil divisão do pico em duas reflexões basais: 2:1 secundário no ombro na parte baixa e esquerda do pico $(\mathrm{d}(001)=1,2 \mathrm{~nm})$ e ilita/mica no cume do pico $(\mathrm{d}(001)=1,02 \mathrm{~nm})$. Com a solução de $\mathrm{NaOH}$ 3,5 mol L-1 , observa-se que a reflexão dos minerais 2:1 secundários passou a ter maior intensidade que o ombro formado pela ilita/mica (lado direito da reflexão basal); em relação à solução de $1,0 \mathrm{~mol} \mathrm{~L}^{-1}$, esse tratamento removeu maior quantidade de gibbsita e caulinita, e a solubilização simultânea de partículas de minerais $2: 1$ secundários com menor tamanho e cristalinidade tornou o pico mais bem definido (menor LMH) $(\mathrm{d}(001)=1,35 \mathrm{~nm}$ Figura 1).

Como alternativa ao método proposto por Jackson et al. (1986) (NaOH $5 \mathrm{~mol} \mathrm{~L}^{-1}$ a quente), deve-se preferir a solubilização apenas parcial da gibbsita e da caulinita (observar a permanência das reflexões (002) - $18,2^{\circ} 2 \theta$ - da gibbsita e (001) - $12,3^{\circ} 2 \theta$ - da caulinta, Figura 1), utilizando-se soluções com concentrações intermediárias de $\mathrm{NaOH}$, a fim de determinar aquela mais favorável para se obter o equilíbrio entre concentração e remoção de minerais 2:1 secundários e facilitar sua análise por DRX.

Tomando os tratamentos no horizonte A do perfil SCA como exemplo (Figura 1 e Quadro 2), com base

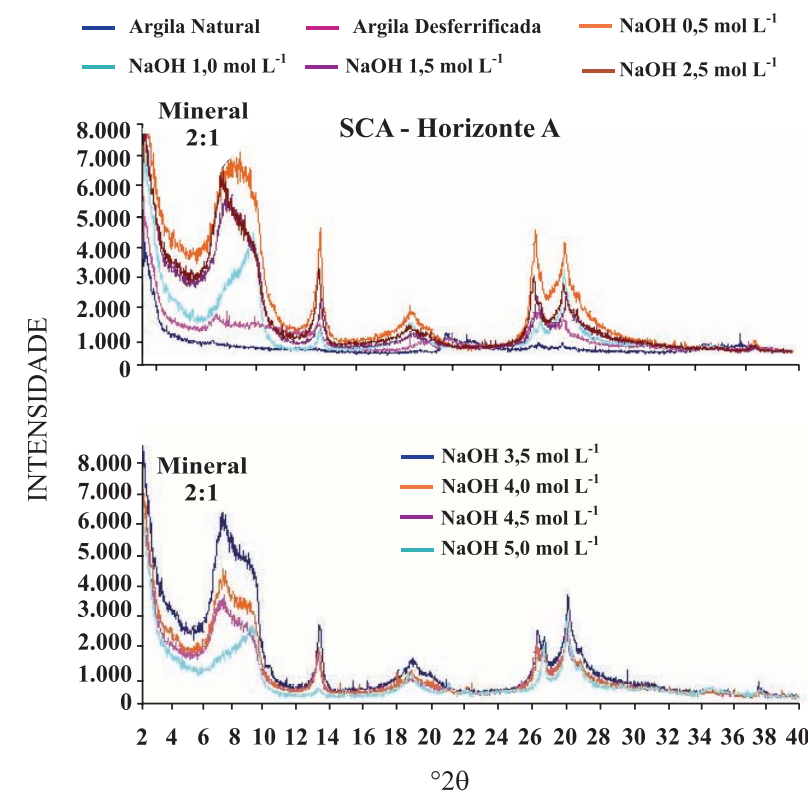

Figura 1. Difratogramas de raios $X$ de amostras orientadas de argila natural e desferrificada, antes e após os tratamentos com diferentes concentrações de $\mathrm{NaOH}$, do horizonte A do perfil do Setor de Ciências Agrárias (SCA) da UFPR. A distância basal d(001) do mineral 2:1 variou de $1,32 \mathrm{~nm}\left(\mathrm{NaOH} 2,5 \mathrm{~mol} \mathrm{~L}^{-1}\right)$ a $1,0 \mathrm{~nm}(\mathrm{NaOH}$ $5 \mathrm{~mol} \mathrm{~L}^{-1}$ ). 
nos valores de intensidade e LMH da reflexão basal, verifica-se que a solução de $\mathrm{NaOH} 3,5 \mathrm{~mol} \mathrm{~L}^{-1}$ foi mais eficiente na concentração de 2:1 secundários. Mesmo que as amostras submetidas ao DCB e aos tratamentos com $\mathrm{NaOH}$ 0,5 e 1,5 mol L-1 apresentem intensidade ligeiramente maior, a escolha da concentração de $3,5 \mathrm{~mol} \mathrm{~L}^{-1}$ deveu-se à melhor definição do pico, ou seja, menor LMH (Quadro 2). Outra característica favorável à concentração de $3,5 \mathrm{~mol} \mathrm{~L}^{-1}$ em relação à de $0,5 \mathrm{~mol} \mathrm{~L}^{-1}$ é o maior valor de d(001) $(1,35 \mathrm{~nm})$ medido no cume do pico para a maior concentração. Para os horizontes $\mathrm{Bi}$ e $\mathrm{C} 1$, a extração com $\mathrm{NaOH}$ $3,5 \mathrm{~mol} \mathrm{~L}^{-1}$ resultou não apenas em reflexões basais de 2:1 secundários com menores LMH, mas também com maiores intensidades que os demais tratamentos.

Para as amostras tomadas em maiores profundidades (horizontes $\mathrm{C} 2$, C3 e C4), naturalmente com maiores teores de minerais $2: 1$, a solução de $\mathrm{NaOH}$ $1,5 \mathrm{~mol} \mathrm{~L}^{-1}$ mostrou-se mais eficiente nesse propósito - observar os gráficos da figura 2 e o maior valor de intensidade e menor de LMH da reflexão basal no quadro 2. Por essa razão, nas demais determinações e interpretações foram tomadas apenas as amostras desferrificadas e tratadas com $\mathrm{NaOH}$ nessas concentrações selecionadas: horizontes A, B e C1 $3,5 \mathrm{~mol} \mathrm{~L}^{-1}$ e horizontes $\mathrm{C} 2$, C3 e C4 - 1,5 $\mathrm{mol} \mathrm{L}^{-1}$.

A proporção de remoção em massa da fração argila desferrificada pelo tratamento com $\mathrm{NaOH} 3,5 \mathrm{~mol} \mathrm{~L}^{-1}$ (horizontes A, B e C1) variou de 411,9 a 615,5 $\mathrm{g} \mathrm{kg}^{-1}$ para o perfil FAZ e de 279,7 a $596,8 \mathrm{~g} \mathrm{~kg}^{-1}$ para o perfil SCA (Quadro 3). Devido a menor capacidade de extração e, provavelmente, aos menores teores de gibbsita e caulinita nas amostras tomadas em maiores profundidades, a remoção em massa pelo tratamento com $\mathrm{NaOH} 1,5 \mathrm{~mol} \mathrm{~L}^{-1}$ (horizontes C2, C3 e C4) foi menor (remoção máxima de 440,4 $\mathrm{g} \mathrm{kg}^{-1}$ ). Considerando os dois tratamentos sequenciais (DCB mais $\mathrm{NaOH}$ ), a concentração máxima da fração argila foi de 212,7 $\mathrm{g} \mathrm{kg}^{-1}$ (amostra SCA, horizonte B: 1.000 $787,3 \mathrm{~g} \mathrm{~kg}^{-1}$ - Quadro 3), evidenciando que, mesmo nas

Quadro 2. Intensidade e largura à meia altura (LMH) da reflexão basal dos minerais 2:1 da fração argila dos horizontes A e C4 do perfil SCA submetida a diferentes tratamentos (gráficos mostrados nas Figuras 1 e 2) ${ }^{(1)}$

\begin{tabular}{|c|c|c|c|c|}
\hline \multirow{2}{*}{ Tratamento } & \multicolumn{2}{|c|}{ Horizonte A } & \multicolumn{2}{|c|}{ Horizonte C4 } \\
\hline & Intensidade & LMH $\left({ }^{\circ} 2 \theta\right)$ & Intensidade & LMH $\left({ }^{\circ} 2 \theta\right)$ \\
\hline Argila Natural & 100 & nd & 4.000 & 2,9 \\
\hline $\mathrm{DCB}$ & 680 & 1,1 & 6.111 & 3,0 \\
\hline $\mathrm{DCB}+\mathrm{NaOH} 0,5$ & 5.780 & 3,6 & 2.038 & 2,7 \\
\hline $\mathrm{DCB}+\mathrm{NaOH} 1,0$ & 3.941 & 2,5 & 7.385 & 2,9 \\
\hline $\mathrm{DCB}+\mathrm{NaOH} 1,5$ & 5.170 & 2,8 & 10.083 & 2,7 \\
\hline $\mathrm{DCB}+\mathrm{NaOH} 2,5$ & 5.460 & 2,9 & 8.462 & 3,0 \\
\hline $\mathrm{DCB}+\mathrm{NaOH} 3,5$ & 5.312 & 2,3 & 5.667 & 3,2 \\
\hline $\mathrm{DCB}+\mathrm{NaOH} 4,0$ & 2.760 & 2,7 & 6.500 & 3,4 \\
\hline $\mathrm{DCB}+\mathrm{NaOH} 4,5$ & 3.889 & 2,5 & 5.235 & 3,9 \\
\hline $\mathrm{DCB}+\mathrm{NaOH} 5,0$ & 3.750 & 2,5 & 1761 & 2,7 \\
\hline
\end{tabular}

(1) Em todos os tratamentos, a concentração de $\mathrm{NaOH}$ está em mol L ${ }^{-1}$. nd - não determinado pela baixa intensidade da reflexão. Para a maior concentração de $\mathrm{NaOH}$, nos dois horizontes, a medida de intensidade e de $\mathrm{LMH}$ refere-se a minerais 2:1 primários (ilita/mica), em virtude da grande remoção dos secundários (ausência de ombro ou cume na região de 1,4 nm - Figuras 1 e 2).


${ }^{\circ} 2 \theta$

Figura 2. Difratogramas de raios X de amostras orientadas de argila natural e desferrificada, antes e após os tratamentos com diferentes concentrações de $\mathrm{NaOH}$, do horizonte $\mathrm{C} 4$ do perfil do Setor de Ciências Agrárias (SCA) da UFPR. A distância basal d(001) do mineral 2:1 variou de 1,58 nm (natural) a 1,0 nm $\left(\mathrm{NaOH} 5 \mathrm{~mol} \mathrm{~L}^{-1}\right)$. 
Quadro 3. Massa de amostra de argila removida com as extrações sequenciais (ditionito-citratobicarbonato (DCB) e NaOH) nos Cambissolos da Região Metropolitana de Curitiba

\begin{tabular}{|c|c|c|c|c|}
\hline Perfil & Horizonte & DCB & $\mathrm{NaOH}^{(1)}$ & Total \\
\hline & & & $-\mathrm{g} \mathrm{kg}^{-1}$ & \\
\hline \multirow[t]{6}{*}{ FAZ } & $\mathrm{A}$ & 187,0 & 411,9 & 598,9 \\
\hline & $\mathrm{B}$ & 134,3 & 496,9 & 631,2 \\
\hline & $\mathrm{C}_{1}$ & 96,2 & 615,5 & 711,7 \\
\hline & $\mathrm{C}_{2}$ & 80,7 & 440,4 & 521,1 \\
\hline & $\mathrm{C}_{3}$ & 81,9 & 102,5 & 184,4 \\
\hline & $\mathrm{C}_{4}$ & 78,5 & 161,3 & 239,8 \\
\hline \multirow[t]{6}{*}{ SCA } & A & 247,4 & 511,0 & 758,5 \\
\hline & B & 190,4 & 596,8 & 787,3 \\
\hline & $\mathrm{C}_{1}$ & 114,2 & 279,7 & 393,9 \\
\hline & $\mathrm{C}_{2}$ & 80,7 & 138,8 & 219,6 \\
\hline & $\mathrm{C}_{3}$ & 73,7 & 200,2 & 273,8 \\
\hline & $\mathrm{C}_{4}$ & 72,2 & 236,3 & 308,5 \\
\hline
\end{tabular}

(1) Solução de $\mathrm{NaOH} 3,5 \mathrm{~mol} \mathrm{~L}^{-1}$ para os horizontes A, B e C1 e $1,5 \mathrm{~mol} \mathrm{~L}^{-1}$ para os horizontes C2, C3 e C4. Remoção em massa da amostra pelos diferentes tratamentos [(peso inicial - peso final)/peso inicial] x 1.000 .

concentrações intermediárias de $\mathrm{NaOH}\left(<5 \mathrm{~mol} \mathrm{~L}^{-1}\right)$, houve expressiva concentração de minerais $2: 1$.

A separação física (centrifugação) da amostra de argila desferrificada em argila fina e grossa também favoreceu a identificação da reflexão basal (001) dos minerais 2:1 secundários (Figura 3), principalmente para as amostras do perfil SCA. No horizonte A desse perfil verificou-se o predomínio de minerais $2: 1$ na argila grossa e no horizonte $\mathrm{C} 4$ da argila fina. Esse comportamento oposto pode ser explicado pela maior facilidade de intemperismo de partículas finas de esmectitas no horizonte A, as quais se mantiveram preservadas em maiores profundidades (horizonte $\mathrm{C} 4$ - 4,2 a 4,5 m), visto que os minerais $2: 1$ secundários na fração argila dos solos da Bacia Sedimentar de Curitiba são, principalmente, herdados do argilito de origem (Lima et al., 1985). A ocorrência preferencial de caulinita [(001) - 12,3 $3^{\circ} 2 \theta$ ] e mica [(001) - 8,9 $\left.{ }^{\circ} 2 \theta\right]$ na argila grossa também favoreceu a concentração dos minerais 2:1 na argila fina no horizonte C4 (Figura 3).

\section{Abundância de minerais 2:1 secundários}

O Cambissolo do Setor de Ciências Agrárias (SCA) apresentou maior abundância de minerais $2: 1$ secundários que o Cambissolo localizado na Fazenda Experimental do Canguiri (FAZ), pois as reflexões basais $(\mathrm{d}(001) \sim 1,4 \mathrm{~nm})$ foram menos intensas neste último solo (Figuras 1, 2, 3 e 4); as relações das intensidades das reflexões basais para as argilas dos horizontes $\mathrm{Ae}$ $\mathrm{C} 4$ submetidas aos tratamentos selecionados de $\mathrm{NaOH}$ para os perfis SCA e FAZ foram de 3,1 e 2,9, respectivamente. O relevo praticamente plano do SCA e a localização do perfil em posição com maior acúmulo de água das chuvas, aliados à baixa permeabilidade do argilito da Formação Guabirotuba (Lima et al., 1985), dificultaram a lixiviação das bases e sílica do solo. Outras evidências da menor drenagem do perfil SCA são a cor mais brunada do horizonte Bi (5YR) e a ocorrência de mosqueado no horizonte C (Quadro 1). Essas condições foram favoráveis à manutenção dos minerais $2: 1$ secundários no solo, uma vez que o próprio material de origem é rico em sílica e esmectita (Massad et al., 1981). Já a localização do perfil da Fazenda Canguiri (terço superior de encosta) contribuiu para a perda de sílica por fluxo lateral da água, e o resultado foi a menor intensidade das reflexões dos minerais 2:1 secundários nos horizontes A, C2, C3 e C4 e ausência de reflexão basal (001) nos horizontes Be C1.
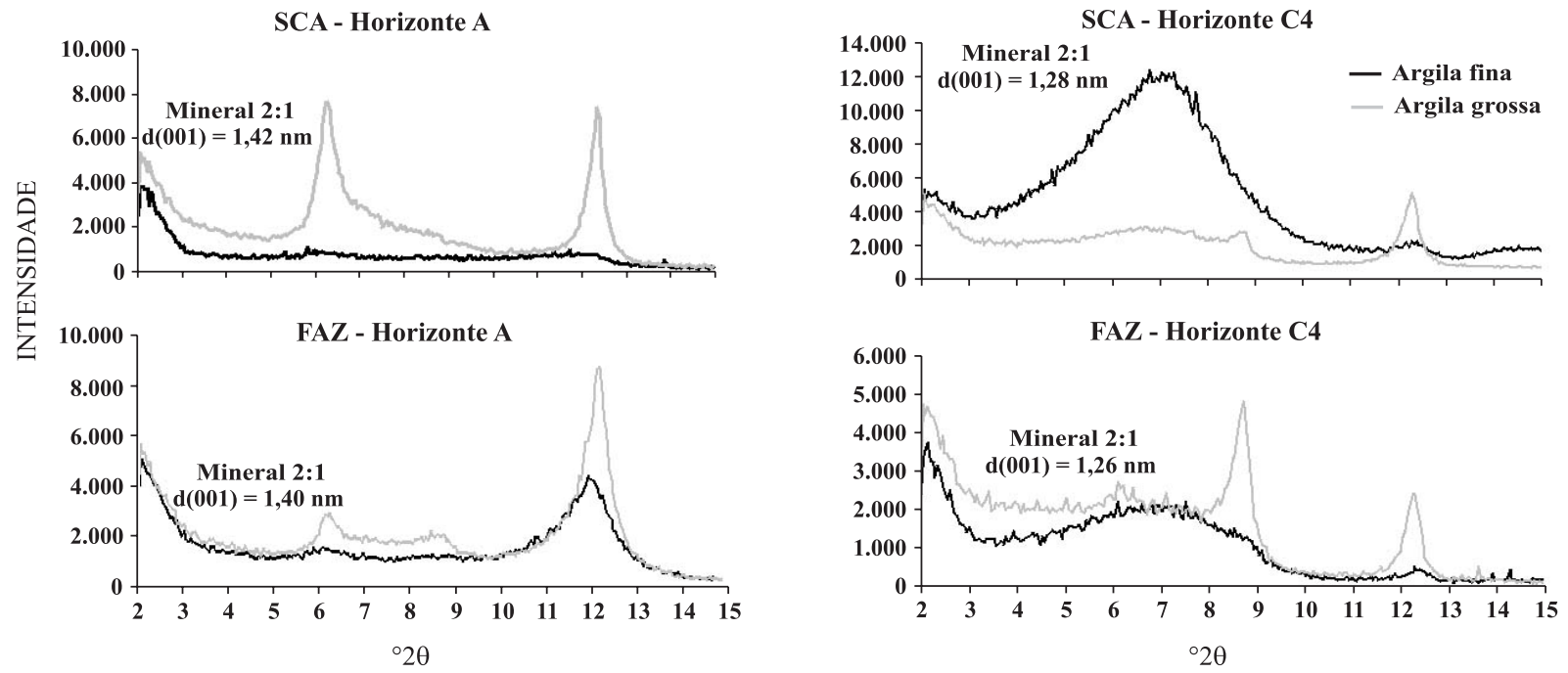

Figura 3. Difratogramas de raios $\mathrm{X}$ de amostras desferrificadas e orientadas de argila fina e grossa dos horizontes A e C4 do perfil do Setor de Ciências Agrárias (SCA) e da Fazenda Experimental do Canguiri (FAZ) da UFPR. 


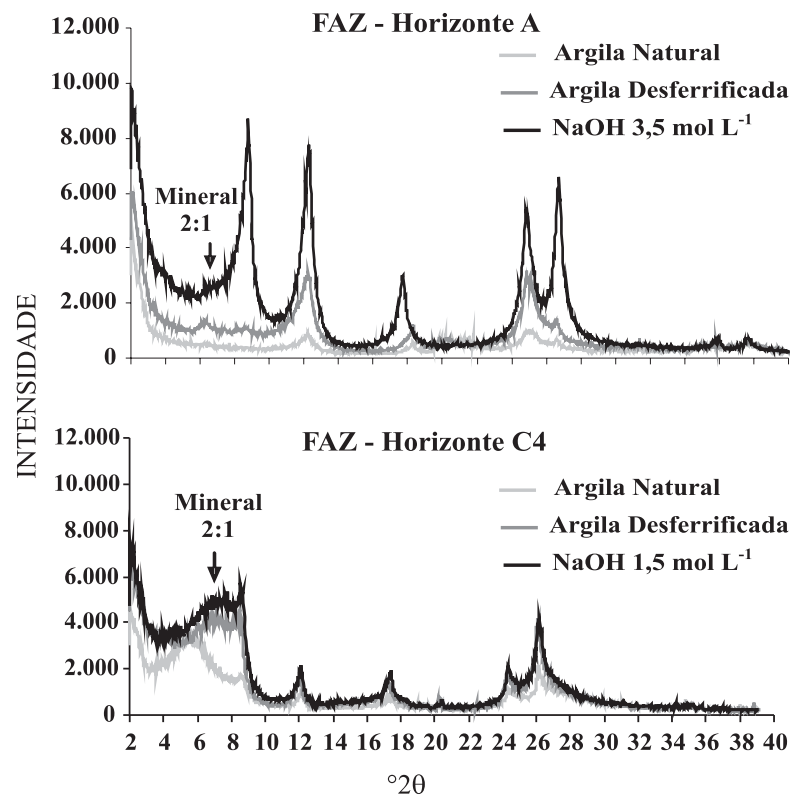

Figura 4. Difratogramas de raios $\mathrm{X}$ de amostras orientadas de argila natural e desferrificada, antes e após os tratamentos com soluções de $\mathrm{NaOH}$, nas concentrações de 3,5 e 1,5 $\mathrm{mol} \mathrm{L}^{-1}$, nos horizontes A e $\mathrm{C} 4$, respectivamente, no perfil da Fazenda Experimental do Canguiri (FAZ) da UFPR. No horizonte A, o espaçamento basal d(001) ficou em torno de $1,41 \mathrm{~nm}$; no horizonte C4, variou de $1,55 \mathrm{~nm}$ (natural) a $1,18 \mathrm{~nm}$ $(\mathrm{NaOH})$.

\section{Identificação da espécie mineral 2:1}

Entre os minerais de argila 2:1 secundários, esmectita e esmectitas com hidroxi-Al entrecamadas (EHE) foram identificadas por meio dos tratamentos auxiliares (saturação com Mg, Mg mais etilenoglicol, $\mathrm{K}$ e $\mathrm{K}$ mais aquecimento) nos horizontes dos solos (Figuras 5 e 6 e Quadro 4).

Nas amostras de argila desferrificada dos horizontes A e B do perfil SCA e do horizonte A do perfil FAZ, a formação de pico em $\mathrm{d}(001) \sim 1,4 \mathrm{~nm}$ com saturação por Mg e manutenção desse espaçamento basal com os tratamentos subsequentes (saturação com $\mathrm{Mg}$ mais etilenoglicol e saturação com K) é indicativo de que o mineral tem sua expansibilidade anulada, devido à presença de hidroxi-Al entrecamadas; contudo, ao aquecer as amostras saturadas com K a $500{ }^{\circ} \mathrm{C}$, ocorreu a destruição das ilhas de hidroxi-Al e o espaçamento basal colapsou para $\mathrm{d}(001) \sim 1,0 \mathrm{~nm}$ (Figura 5a). De acordo com Whittig \& Allardice (1986), esse comportamento diferenciado é típico de minerais 2:1 HE. Para confirmar que esse mineral é EHE, e não vermiculita HE (VHE), foi necessário analisar as amostras tratadas com $\mathrm{NaOH} 3,5 \mathrm{~mol} \mathrm{~L}^{-1}$ (concentração selecionada para os horizontes superficiais) e submetidas aos mesmos tratamentos auxiliares. Com a destruição das ilhas de hidroxi-Al pela solução de $\mathrm{NaOH}$ (Brown, 1953; Dixon \& Jackson, 1959) e a saturação com Mg mais etilenoglicol, verificou-se a expansão do mineral e a ampliação do espaçamento basal para $\mathrm{d}(001)>1,5 \mathrm{~nm}$ e $\mathrm{d}(001)<1,8 \mathrm{~nm}$ (Figura 5b).

Usando a DRX, Melo (1998) também observou a remoção de ilhas de hidroxi-Al nas entrecamadas de mineral $2: 1$ e redução do espaçamento basal de 1,4 para $1,0 \mathrm{~nm}$ de um mineral interestratificado ilita/ 2:1 HE. Entretanto, esse autor não realizou tratamentos complementares para comprovar se as camadas eram de VHE ou EHE.

A presença de hidroxi-Al nas entrecamadas de vermiculita (VHE) e esmectitas (EHE) pode dar estabilidade aos minerais $2: 1$, termodinamicamente instáveis em condições de maior intemperismo e remoção de sílica (Harris et al., 1988; Barnhisel \& Bertsch, 1989). Por esse motivo, provavelmente, o EHE foi mantido no horizonte A da Fazenda Canguiri, mesmo com a ocorrência limitada de minerais $2: 1$ nesse perfil (Figuras 3 e 4 e Quadro 4).

No horizonte $\mathrm{C}$, em todas as profundidades do perfil SCA e para profundidades superiores a $1,5 \mathrm{~m}$ no perfil FAZ, verificou-se a presença de esmectitas, pois, ao saturar as amostras de argila com Mg mais etilenoglicol, o espaçamento basal aumentou para $\mathrm{d}(001) \sim 1,8 \mathrm{~nm}$, devido à expansão do mineral (Figura 6). Pela intensificação dos picos, os teores de

Quadro 4. Identificação das esmectitas dioctaedrais na fração argila dos Cambissolos da Região Metropolitana de Curitiba

\begin{tabular}{|c|c|c|}
\hline \multirow{2}{*}{ Horizonte } & \multicolumn{2}{|c|}{ Coleta } \\
\hline & Fazenda Experimental do Canguiri (UFPR) & SCA - Setor de Ciências Agrárias (UFPR) \\
\hline A & Resíduo de Montmorilonita $\mathrm{HE}^{(1)}$ e Beidelita/Nontronita HE & Montmorilonita HE e Beidelita/Nontronita HE \\
\hline $\mathrm{B}$ & Ausência de Esmectitas & Montmorilonita HE e Beidelita/Nontronita HE \\
\hline $\mathrm{C} 1$ & Ausência de Esmectitas & Montmorilonita e Beidelita/Nontronita \\
\hline $\mathrm{C} 2$ & Montmorilonita e Beidelita/Nontronita & Montmorilonita e Beidelita/Nontronita \\
\hline C3 & Montmorilonita e Beidelita/Nontronita & Montmorilonita e Beidelita/Nontronita \\
\hline $\mathrm{C} 4$ & Montmorilonita e Beidelita/Nontronita & Montmorilonita e Beidelita/Nontronita \\
\hline
\end{tabular}

(1) HE: hidroxi-Al entrecamadas. 
(a) SCA - Horizonte A - Argila Desferrificada

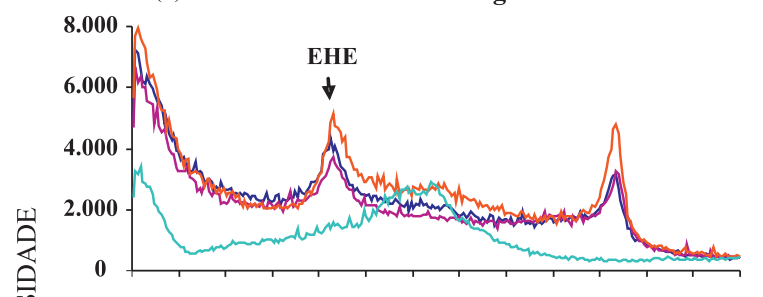

(b) SCA - Horizonte A - NaOH 3,5 mol L-1

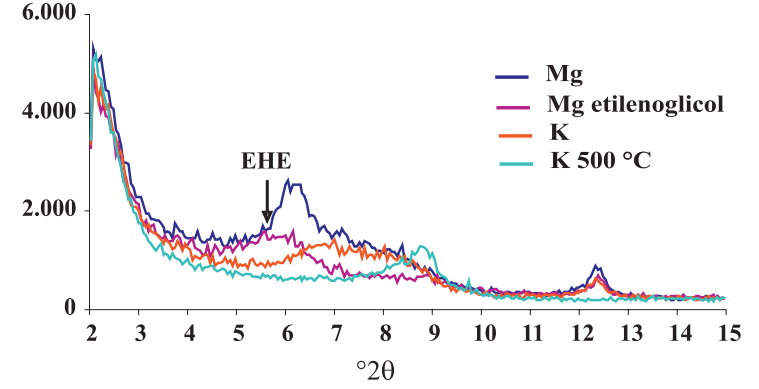

Figura 5. Difratogramas de raios $X$ de amostras orientadas de argila do horizonte A do Setor de Ciências Agrárias (SCA) da UFPR, submetidas a tratamentos auxiliares: a) desferrificada; b) desferrificada e tratada com solução de $\mathrm{NaOH}$ $3,5 \mathrm{~mol} \mathrm{~L}^{-1}$. EHE - esmectita com hidroxi-Al entrecamadas. Espaçamento basal d(001): (a) $\mathrm{Mg}$ - 1,42 nm, Mg etilenoglicol - 1,42 nm, K $1,42 \mathrm{~nm}$; $\mathrm{K} 550{ }^{\circ} \mathrm{C}$ - 1,09 nm; (b) $\mathrm{Mg}$ - 1,4 nm; $\mathrm{Mg}$ etilenoglicol - $1,60 \mathrm{~nm}$; $\mathrm{K}-1,26 \mathrm{~nm}$; $\mathrm{K} 550{ }^{\circ} \mathrm{C}$ $1,00 \mathrm{~nm}$.

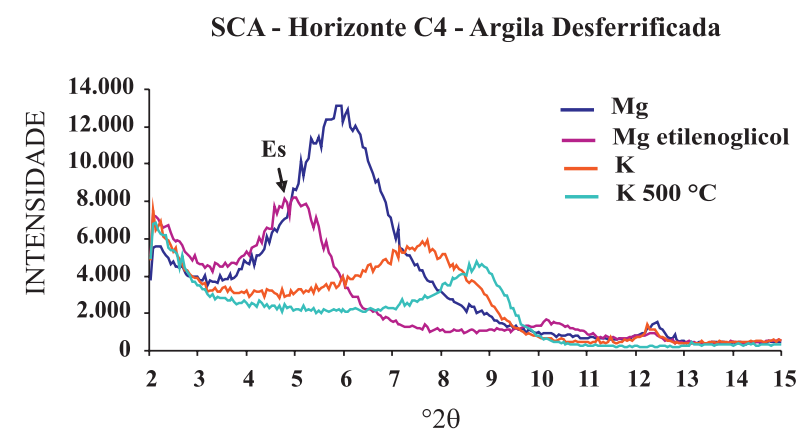

Figura 6. Difratogramas de raios $X$ de amostras orientadas de argila desferrificada do horizonte C4 do Setor de Ciências Agrárias (SCA) da UFPR, submetidas aos tratamentos auxiliares. Es esmectita. Espaçamento basal d(001): Mg 1,5 nm; Mg etilenoglicol - 1,80 nm; $K$ - 1,15 nm; $K$ $550{ }^{\circ} \mathrm{C}-1,00 \mathrm{~nm}$.

esmectitas crescem proporcionalmente à profundidade dos horizontes, em ambos os perfis.

\section{Identificação da espécie mineral do grupo das esmectitas dioctaedrais}

Foram identificadas montmorilonita e beidelita/ nontronita, todas pertencentes à classe das esmectitas dioctaedrais (Quadro 4). No procedimento utilizado para identificar as esmectitas dioctaedrais (teste de Greene-Kelly), o Li penetra na estrutura dos minerais e ocupa posições octaedrais vagas. Se a carga na camada do mineral for originada na lâmina octaedral, o Li neutraliza o déficit de carga positiva e a solvatação com glicerol não provoca expansão; por isso, o teste só é eficiente nas esmectitas dioctaedrais. Assim, o pico intenso em 1,0 $\mathrm{nm}$ na amostra saturada com $\mathrm{Li}$ dividiu-se em duas reflexões basais após a saturação da amostra com Li mais etilenoglicol (Figuras 7 e 8): a montmorilonita não expandiu e produziu um pico em aproximadamente $1,0 \mathrm{~nm}$; beidelita/nontronita não tiveram suas cargas neutralizadas e expandiram quando saturadas com etilenoglicol, formando picos entre 1,4 e 1,7 $\mathrm{nm}$.

Nos horizontes onde ocorreram esmectitas (horizonte C - Figura 6) foi possível identificá-las apenas em argila desferrificada (DCB) (Figura 7). Contudo, nos horizontes onde ocorreu EHE (horizontes superficiais), procedeu-se ao teste de Greene-Kelly em amostra previamente tratada com DCB e com solução de $\mathrm{NaOH} 3,5 \mathrm{~mol} \mathrm{~L}^{-1}$ (Figura 8), para remoção das ilhas de hidroxi-Al.

Neste estudo, dado o baixo teor de Fe do material de origem, indicado pelos baixos teores de $\mathrm{Fe}_{2} \mathrm{O}_{3}$ extraídos pelo DCB em Cambissolos da Bacia Sedimentar de Curitiba (teores variando de 51,2 a $114,1 \mathrm{~g} \mathrm{~kg}^{-1}$ - Pires et al., 2007), suspeita-se que entre as esmectitas dioctaedrais com carga nas lâminas tetraedrais (beidelita/nontronita) deve haver baixa ocorrência de nontronita ( $\mathrm{Fe}^{3+}$ na lâmina octaédrica). Segundo Wilson (1976) e Garcia-Romero et al. (2005), a nontronita é uma esmectita rara nos solos, formada, preferencialmente, sob condições de hidrotermalismo em alguns tipos de materiais de origem. Reforçando a influência do material de origem na formação dos minerais $2: 1$, em serpentinito (rocha ultrabásica rica em Mg) podem ser encontradas esmectitas magnesianas (trioctaedrais), como a saponita (Pinto \& Kämpf, 1997; Vidal-Torrado et al., 2006).

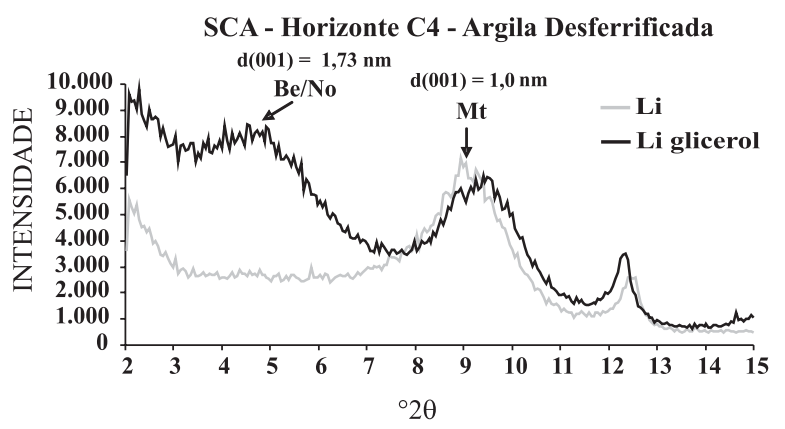

Figura 7. Difratogramas de raios $\mathrm{X}$ de amostras orientadas de argila desferrificada do horizonte C4 do perfil do Setor de Ciências Agrárias (SCA) da UFPR, submetidas ao teste de Greene-Kelly. Be - beidelita; Mt - montmorilonita; No nontronita. 


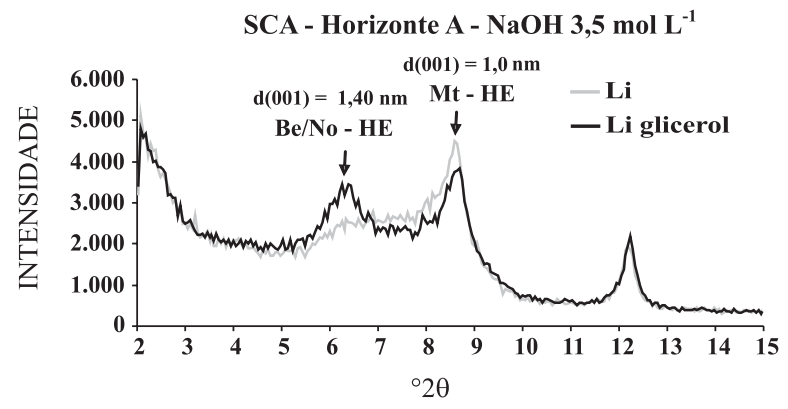

Figura 8. Difratogramas de raios $\mathrm{X}$ de amostras orientadas de argila desferrificada e tratada com solução de $\mathrm{NaOH} 3,5 \mathrm{~mol} \mathrm{~L}^{-1}$ do horizonte A do perfil do Setor de Ciências Agrárias (SCA) da UFPR, submetidas ao teste de Greene-Kelly.

\section{CONCLUSÕES}

1. O método clássico de extração da caulinita, com solução de $\mathrm{NaOH}$ 5,0 mol L-1 a quente, não deve ser aplicado para concentração de minerais 2:1 secundários na fração argila de Cambissolos da Bacia Sedimentar de Curitiba. A alta energia de extração da solução também removeu grande parte dos minerais 2:1 secundários. O emprego de solução de $\mathrm{NaOH}$ 3,5 mol L-1 em amostra de argila desferrificada possibilitou, com maior eficiência, a identificação de minerais 2:1 secundários por difratometria de raios $\mathrm{X}$ nos horizontes A, Bi e C1. Nas amostras tomadas em maiores profundidades (horizontes $\mathrm{C} 2$, $\mathrm{C} 3$ e C4), devido aos maiores teores de minerais $2: 1$ secundários e ao menor tamanho dos cristais (argila fina), a solução de $\mathrm{NaOH} 1,5 \mathrm{~mol} \mathrm{~L}^{-1}$ foi mais eficiente para esse propósito.

2. No horizonte $A$, os minerais $2: 1$ secundários concentraram-se na fração argila grossa, compatível com o maior grau de intemperismo desse horizonte. Comportamento oposto foi verificado para a amostra do horizonte $\mathrm{C} 4$.

3. Identificou-se esmectita com hidroxi-Al entrecamadas nos horizontes mais superficiais e esmectita nas amostras do horizonte C. O teste de Greene-Kelly (saturação com Li) foi eficiente na identificação das esmectitas dioctaedrais montmorilonita e beidelita/nontronita.

\section{LITERATURA CITADA}

ALBA, M.D.; CASTRO M.A.; NARANJO, M. \& PERDIGÓN, A.C. Structural localization of $\mathrm{Al}^{3+}$ ions in aluminosilicates: Application of heteronuclear chemical shift correlation to 2:1 Phyllosilicates. Phys. Chem. Miner., 31:195-202, 2004 .

BARNHISER, R.I. \& BERTSCH, P.M. Chlorites and hydroxyinterlayered vermiculite and smectite. In: DIXON, J.B. \& WEED, S.B., eds. Minerals in soil environments. 2.ed. Madison, Soil Science Society of America, 1989. p.729788 .
BARRÉ, P.; VELDE, B.; FONTAINE, C.; CVATEL, N. \& ABBADIE, L. Which 2:1 Clay minerals are involved in the soil potassium reservoir? Insights from potassium addition or removal experiments on three temperate grassland soil clay assemblages. Geoderma, 146:216-223, 2008.

BIGARELLA, J.J. \& SALAMUNI, R. Caracteres texturais dos sedimentos da Bacia de Curitiba. Geologia. B. UFPR, 7:1164, 1962.

BOMBIN, M. \& KLAMT, E. Evidências paleoclimáticas em solos do Rio Grande do Sul. In: CONGRESSO BRASILEIRO DE GEOLOGIA, 28., Porto Alegre, 1974. Anais. Porto Alegre, 1974. p.183-194.

BORCHARDT, G. Smectites. In: DIXON, J.B. \& WEED, S.B., eds. Minerals in soil environments. 2.ed. Madison, Soil Science Society of America, 1989. p.675-727.

BORTOLUZZI, E.C.; PERNES, M. \& TESSIER, D. Interestratificado caulinita-esmectita em um Argissolo desenvolvido a partir de rocha sedimentar do Sul do Brasil. R. Bras. Ci. Solo, 31:1291-1300, 2007.

BROWN, G. The dioctahedral analogue of vermiculite. Clay Miner. B., 2:64-69, 1953.

CHURCHMAN, G.J. The alteration and formation of soil minerals by weathering. In: SUMNER, M.E., ed. Handbook of soil science. Boca Raton, CRC Press, 2000. p.F3-F76.

CORRÊA, M.M.; KER, J.C.; MENDONÇA, E.S.; RUIZ, H.A. \& BASTOS, R.S. Atributos físicos, químicos e mineralógicos de solos da região das várzeas de Sousa (PB). R. Bras. Ci. Solo, 27:311-324, 2003.

DIXON, J.B. \& JACKSON, M.L. Dissolution of interlayers from intergradient soil clays after preheatint at $400{ }^{\circ} \mathrm{C}$. Science, 129:1616-1617, 1959.

DRITS, V.A.; SAKHAROV, B.A.; SALYN, A.L. \& LINDGREEN, $H$. Determination and distribution of fixed ammonium in illite-smectite using a modified X-ray diffraction technique: Application to soil source rocks of the western Greenland. Am. Miner., 90:71-85, 2005.

DUR, J.C.; ELSASS, F.; CHAPLAIN, V. \& TESSIER, D. The relationship between particle-size distribution by laser granulometry and image analysis by transmission electron microscopy in a soil clay fraction. Eur. J. Soil Sci., 55:265-270, 2004.

EMPRESA BRASILEIRA DE PESQUISA AGROPECUÁRIA EMBRAPA. Levantamento de reconhecimento dos solos do Estado do Paraná. Londrina, 1984. Tomo I. p.221-312.

EMPRESA BRASILEIRA DE PESQUISA AGROPECUÁRIA EMBRAPA. Sistema brasileiro de classificação de solos. 2.ed. Rio de Janeiro, 2006. 306p.

GARCIA-ROMERO, E.; VEGAS, J.; BALDONEDO, J. L. \& MARFIL, R. Clay minerals as alteration products in basaltic volcaniclastic deposits of La Palma (Canary Islands, Spain). Sedim. Geol., 174:237-253, 2005. 
GEE, G.W. \& BAUDER, J.W. Particle-size analysis. In: KLUTE, A., ed. Methods of soil analysis. Part 1: Physical and mineralogical methods. Madison, American Society of Agronomy, 1986. p.383-412.

GREENE-KELLY, R. Identification of the montmorillonoides. J. Soil Sci., 4:233-237, 1953.

HARRIS, W.G.; HOLLIEN, K.A.; YUAN, T.L.; BATES, S.R. \& ACREE, W.A. Nonexchangeable potassium associated with hydroxy-interlayered vermiculite from Coastal Plain soils. Soil Sci. Soc. Am. J., 52:1489-1492, 1988.

JACKSON, M. L.; LIM, C. H. \& ZELAZNY, L.W. Oxides, hydroxides, and aluminosilicates. In: KLUTE, A., ed. Methods of soil analysis. Part 1: Physical and mineralogical methods. Madison, American Society of Agronomy, 1986. p.101-150.

JACKSON, M.L. Soil chemical analysis - advanced course. Madison, Prentice-Hall, 1979. 895p.

KAHLE, M.; KLEBER, M. \& JAHN, R. Review of XRD-based quantitative analyses of clay minerals in soils: The suitability of mineral intensity factors. Geoderma, 109:191-205, 2002

KLUG, H.P. \& ALEXANDER, L.E. X-ray diffraction procedures for polycrystalline and amorphous materials. New York, John Wiley \& Sons, 1954. 716p.

KOPPI, A.J. \& SKJEMSTAD, J.O. Soil kaolins and their genetic relationships in southeast Queensland, Australia. J. Soil Sci., 32:661-672, 1981

KUNZE, G.W. \& DIXON, J.B. Pretreatment for mineralogical analysis. In: KLUTE, A., ed. Methods of soil analysis. Part 1: Physical and mineralogical methods. Madison, American Society of Agronomy, 1986. p.91-100.

LEMOS, R.C. \& SANTOS, R.D. Manual de descrição e coleta de solo no campo. 5.ed. Viçosa, MG, Sociedade Brasileira de Ciência do Solo, 2005. 92p.

LIM, C.H. \& JACKSON, M.L. Expandable phyllosicate reactions with lithium on heating. Clays Clay Miner., 34:346-352, 1986.

LIMA, V.C.; DEMATTÊ, J.L.I. \& MONIZ, A.C. Mineralogia da argila do Rubrozem (Palehumult), Bacia de Curitiba Paraná. R. Bras. Ci. Solo, 1:81-85, 1985.

MAACK, R. Geografia física do Estado do Paraná. Curitiba, Codepar, 1969. 180p.

MASSAD, F.; ROCHA, J.L.R. \& YASSUDA, A.J. Algumas características geotécnicas de solos da Formação Guabirotuba. In: SIMPÓSIO BRASILEIRO DE SOLOS TROPICAIS EM ENGENHARIA, Rio de Janeiro, 1981. Anais. Rio de Janeiro, ABMS, 1981. p.706-723.

McBRIDE, M.B. Environmental chemistry of soil. New York, Oxford University Press, 1994. 406p.

MEHRA, O.P. \& JACKSON, M.L. Iron oxide removal from soils and clay by a dithionite-citrate system buffered with sodium bicarbonate. Clays Clay Miner., 7:317-327, 1960.
MELFI, A.J.; MONTES, C.R.; CARVALHO, A. \& FORTI, M.C. Use of pedological maps in the identification of sensitivity of soils to acidic deposition: Application to Brazilian soils. An. Acad. Bras. Ci., 76:139-145, 2004.

MELO, V.F. Potássio e magnésio em minerais de solos e relação entre propriedades da caulinita com formas não trocáveis destes nutrientes. Viçosa, MG, Universidade Federal de Viçosa, 1998. 205p. (Tese de Doutorado)

MELO, V.F.; CORRÊA, G.F.; MASCHIO, P.A.; RIBEIRO, A.N. \& LIMA, V.C. Importância das espécies minerais no potássio total da fração argila de solos do Triângulo Mineiro. R. Bras. Ci. Solo, 27:807-819, 2003.

MELO, V.F.; SCHAEFER, C.E.G.R.; NOVAIS, R.F.; SINGH, B. \& FONTES, M.P.F. Potassium and magnesium in clay minerals of some Brazilian soil as indicated by a sequential extraction procedure. Comm. Soil Sci. Plant Anal., 33:2203$2225,2002$.

MELO, V.F.; SINGH, B.; SCHAEFER, C.E.G.R.; NOVAIS, R.F. \& FONTES, M.P.F. Chemical and mineralogical properties of kaolinite-rich Brazilian soils. Soil Sci. Soc. Am. J., 65:1324-1333, 2001.

MONIZ, A.C.; GRANDE, M.A. \& OLIVEIRA, V. Solos do trecho Cabo Frio-Xerém (RJ): Influência de regimes pluviais e de material de origem na pedogênese. R. Bras. Ci. Solo, 14:205-214, 1990.

NDAYIRAGIJE, S. \& DELVAUX, B. Coexistence of allophone, gibbsite, kaolinite and hydroxyl-Al-interlayered 2:2 Clay minerals in perudic Andosol. Geoderma, 117:203-214, 2003.

NORRISH, K. \& TAYLOR, M. The isomorphous replacement of iron by aluminium in soil goethites. J. Soil Sci., 12:294306, 1961.

PAI, C.W.; WANG, M.K.; CHIU. C.Y. \& HWONG, J.L. Hydroxyinterlayered minerals of forest soils in A-Li Mountain, Taiwan. Geoderma, 123:245-255, 2004.

PINTO, L.F.S. \& KAMPF, N. Balanço geoquímico de solos derivados de rochas básico-ultrabásica no ambiente subtropical do Rio Grande do Sul. R. Bras. Ci. Solo, 21:651658, 1997.

PIRES, A.C.D.; MELO, V.F.; MOTTA, A.C.V. \& LIMA, V.C. Majors soil classes of the metropolitan region of Curitiba (PR), Brazil: I - Mineralogical Characterization of the Sand, Silt and Clay Fractions. Braz. Arch. Biol. Technol., 50:169181, 2007.

REID-SOUKUP, D. \& ULREY, A.L. Smectites. In: DIXON, J.B. \& SCHULZE, D.G., eds. Soil mineralogy with environmental applications. Madison, Soil Science Society of America, 2002. p.467-499.

RIBEIRO, L.P.; VOLKOFF, B. \& MELFI, A.J. Evolução mineralógica das argilas em solos vérticos do Recôncavo Baiano. R. Bras. Ci. Solo, 14:263-268, 1990.

SALAMUNI, E. \& STELLFELD, M.C. Banco de dados geológicos geo-referenciados da Bacia Sedimentar de Curitiba (PR) como base de sistema de informação geográfica (SIG). B. Paranaense Geoci., 49:21-32, 2001. 
SCHULZE, D.G. An introduction to soil mineralogy. In: DIXON, J.B. \& WEED, S.B., eds. Minerals in soil environments. 2.ed. Madison, Soil Science Society of America, 1989. p.11-34.

SINGH, B. \& GILKES, R.J. Concentration of iron oxides from soil clays by $5 \mathrm{M} \mathrm{NaOH}$ treatment: The complete removal of sodalite and kaolin. Clay Miner., 26:463-472, 1991.

SOUZA JÚNIOR, I.G.; COSTA, A.C.S.; SAMBATTI, J.A.; PETERNELE, W.S.; TORMENA, C.A.; MONTES, C.R. \& CLEMENTE, C.A. Contribuição dos constituintes da fração argila de solos subtropicais à área superficial específica e à capacidade de troca catiônica. R. Bras. Ci. Solo, 31:1355-1365, 2007.

TOURNASSAT, C.; NEAMAN, A.; VILLIERAS, F.; BOSBACH, D. \& CHARLET, L. Nanomorphology of montmorillonite particles: Estimation of the clay edges sorption site density by low-pressure gas adsorption and AFM observations. Am. Miner., 88:1989-1996, 2003.
VIDAL-TORRADO, P.; MACIAS, F.; CALVO, R.; CARVALHO, S.G. \& SILVA, A.C. Gênese de solos derivados de rochas ultramáficas serpentinizadas no Sudoeste de Minas Gerais. R. Bra. Ci. Solo, 30:523-541, 2006.

VOLKOFF, B. \& RIBEIRO, L.P. O ferro em solos vermelhos Latossólicos e Podzólicos da região de Jequié (BA). R. Bras. Ci. Solo, 3:162-168, 1979.

WILSON, M.J. Exchange properties and mineralogy of some soils derived from lavas of lower old red sandstone (devonian) age. II. Mineralogy. Geoderma, 15:289-304, 1976.

WITTHIG, L.D. \& ALLARDICE, W.R. X - Ray diffraction techniques. In: KLUTE, A., ed. Methods of soil analysis. Part 1: Physical and mineralogical methods. Madison, American Society of Agronomy, 1986. p.331-362. 
